\title{
Seyrek Görülen Bir Konjenital Hipotoni Vakası : Walker Warburg Sendromu
}

\author{
A Rare Case of Hypotonic Infant: Walker Warburg Syndrome \\ Selen HÜRMÜZLÜ ${ }^{1}$, Serhat EMEKSIZZ ${ }^{2}$, Yasemin Men ATMACA ${ }^{1}$ \\ Ganime AYAR ${ }^{1}$, Alev GÜVEN ${ }^{3}$
}

1. S.B. Üniversitesi Ankara Çocuk Sağllğ̆ ve Hastalıkları Hematoloji Onkoloji Ĕ̆itim ve Araștırma Hastanesi, Çocuk Sağlığı ve Hastalıkları, Ankara, Türkiye

2. S.B. Üniversitesi Ankara Çocuk Sağlı̆̆ı ve Hastalıkları Hematoloji Onkoloji Eğitim ve Araştırma Hastanesi, Çocuk Yoğun Bakım Kliniği, Ankara, Türkiye

3. S.B. Üniversitesi Ankara Çocuk Să̆llğı ve Hastalıkları Hematoloji Onkoloji Ĕgitim ve Araştırma Hastanesi, Çocuk Sağlı̆̆ ve Hastalıkları, Çocuk Nöroloji, Ankara, Türkiye

\section{$\ddot{O Z Z E T}$}

Konjenital muskuler distrofiler (KMD) nadir görülen, infant döneminde kas güçsüzlüğü ve motor gelişimde gecikme ile kendini gösteren bir grup hastalıktır. Bunların en ağır formlarından biri Walker Warburg Sendromu (WWS)' dur. WWS otozomal resesif geçişli, beyin ve göz anomalilerinin eşlik ettiği bir hastallktır. Beyinde tip 2 lizensefali, beyaz cevherde hipomyelinizasyon, hidrosefali, korpus kallosum agenezisi, gözde katarakt, optik sinir displazisi, retinal displazi, lens defektleri görülür. Destek tedavisi verilse de oldukça mortal seyreder, ortalama yaşam ömrü dört ay civarındadır. Burada, klinik ve görüntüleme yöntemleriyle WWS düsünülen, kas biyopsisinde alfa distroglikan eksikliği görülerek tanisı desteklenen bir olgu sunulmustur.

Anahtar Kelimeler: hipotonik infant, muskuler distrofi, walker walburg

\section{ABSTRACT}

Congenital muscular dystrophies are a group of rarely seen muscle diseases. They are recognized with muscle weakness and motor delay on infancy. The most severe form of is Walker Warburg Syndrome (WWS). WWS is a rarely seen autosomal recessive inherited disease with serebral and eye abnormalities. Type 2 lissencephaly, hypomyelination in whitematter, hydrocephalus, corpuscallosum agenesis are pathological findings of brain; also cataract, optic nerve dysplasia, retinal dysplasia, lens defects can be detected on eyes. Even with pallative care is given, median survival age is about four months. In this case we suspected WWS with clinical and radiological findings, and performed a muscle biopsy which is shown alpha dystrogly can deficiency.

Keywords: hypotonic infant, muscular dystrophy, walker walburg

\section{GÍRIŞ}

Walker Warburg Sendromu genetik geçiş gösteren; beynin, kasların ve gözlerin gelişimini etkileyen nadir görülen bir hastalıktır. Konjenital muskuler distrofiler içinde yer alan ve en mortal seyreden sendromdur. Dünya genelinde $1 / 60.500$ doğumda görülür ve otozomal resesif geçiş gösterir (1).

\section{İletişim}

Sorumlu Yazar: Dr. Selen HÜRMÜZLÜ

Adres: S.B. Üniversitesi Ankara Çocuk Sağlığı ve Hastalıkları Hematoloji Onkoloji Eğitim ve Araștırma Hastanesi, Ankara

Tel: +90 (506) 7057229

E-Posta: selenhurmuzlu@gmail.com

Makale Geliş: 25.08.2018

Makale Kabul: 15.11.2018

DOI: http://dx.doi.org/10.16948/zktipb.455091
Hastalar doğumdan itibaren hipotoniktirler, genelde süt çocukluğu döneminde tanı alırlar. WWS'unda gelişme geriliği hastaların hepsinde görülür, nöbet eşlik edebilir. Kraniyal görüntülemelerde tip 2 lizensefali beyaz cevherde hipomyelinizasyon, hidrosefali, korpus kallosum agenezisi saptanır; göz muayenesinde katarakt, optik sinir displazisi, retinal displazi, lens defektleri görülür. Beyin ve göz anomalilerinin dişında düşük kulak, yarık damak dudak, inmemiş testis eşlik edebilir. Laboratuvar bulgularında ciddi kreatinin kinaz yüksekliği tespit edilir. Kas biyopsisinde alfa distroglikanın görülmemesi ile tanı konulur (2). Burada, klinik ve görüntüleme yöntemleriyle WWS düşünülen, kas biyopsisinde alfa distroglikan eksikliği görülerek tanısı desteklenen bir olgu sunulmuştur.

\section{OLGU}

Dört aylık erkek hasta 22 yaşında annenin akraba evliliği sonucu üçüncü gebeliğinden üçüncü yaşayan olarak, 37 haftalık vaginal yol ile 2750 gram, apgar 4/7 ile hastanede doğmuş. Doğumda ensefalosel ve anal atrezi saptanması üzerine opere edilmiș ve üç ay yoğun bakım takibi sonrasında taburcu edilmiș. Taburculuğunun birinci ayında solunum sikıntısı ile hastanemiz acil servisine başvurdu ve bronkopnömoni tanısı ile yoğun bakım ünitemize yatırıldı. Entübe edilerek mekanik ventilatöre bağland1.

Fizik muayenesinde; kaşektik görünümde, vücut ağırlığı ve boyu üç persentil altındaydı, mikrosefali, düşük kulak ve bilateral ekzoftalmus, sağ gözde korneada opasite dikkati çekmekteydi (Şekil 1).

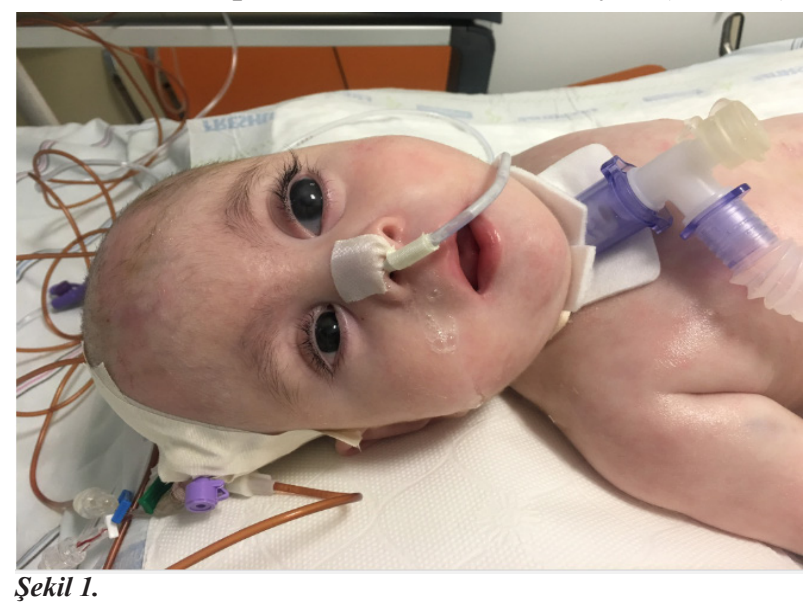


Cildi kuru ve soluktu. Solunum muayenesinde takipne ve bilateral yaygin ralleri vard1. Nöromuskuler muayenesinde yaygin hipotonisite, hiporefleksi saptand1 (Şekil 2).

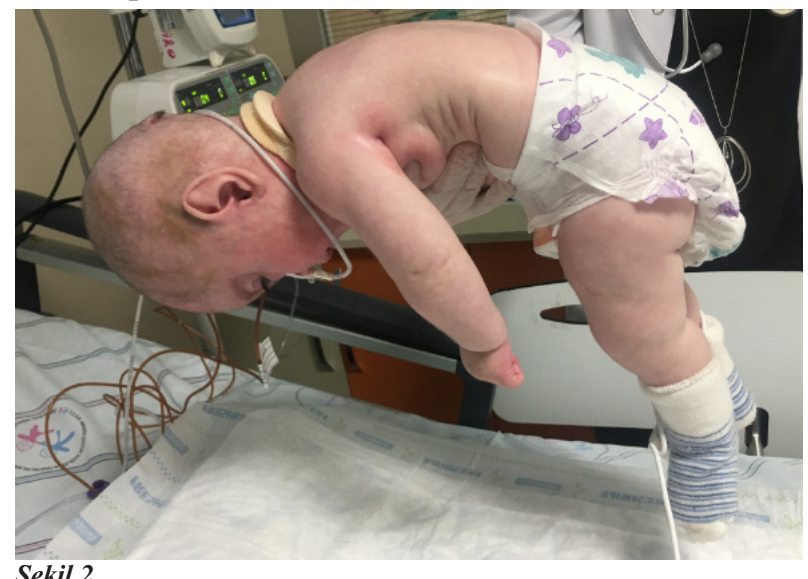

Laboratuvar incelemelerinde WBC: 18.9103 / $\mu \mathrm{L}, \mathrm{Hb}: 11.5 \mathrm{~g} / \mathrm{dl}$, plt:411000 $103 / \mu \mathrm{L}$, üre: $19 \mathrm{mg} / \mathrm{dl}$, kreatinin: $0.50 \mathrm{mg} / \mathrm{dl}$ olarak normal, AST:152 U/L, ALT:81 U/L, kreatininfosfokinaz (CK): 4590 U/L olarak yüksek bulundu. Kas güçsüzlügüü etyolojisi açısından bakılan tiroid fonksiyonları ve vitamin B12 düzeyi normaldi. Batın ultrasonu normal sonuçland. Ekokardiyografide patoloji saptanmadi.

CK yüksekliği ve hipotonisite etyolojisi araştırılmak üzere çekilen kraniyal manyetik rezonans (MR) görüntülemede; kalvaryumda mikrosefali, her iki serebral hemisferde yaygin polimikrogiri, lizensefali, sulkuslarda silinme, giral yapılarda kayı, kortekste belirgin kalınlaşma saptandı. Bilateral serebral beyaz cevherde hipomiyelinizasyonu düşündüren T1A sekanslarda hipodens T2A sekanslarda hiperintens yaygın patolojik sinyal değişiklikleri görüldü. Bazal ganglion ve talamuslarda belirgin dismorfi, ponsta hipoplazi, serebellar kortikal malformasyon izlendi. Optik kiazma ve her iki optik sinir belirgin hipoplazik görünümdeydi (Şekil 3).

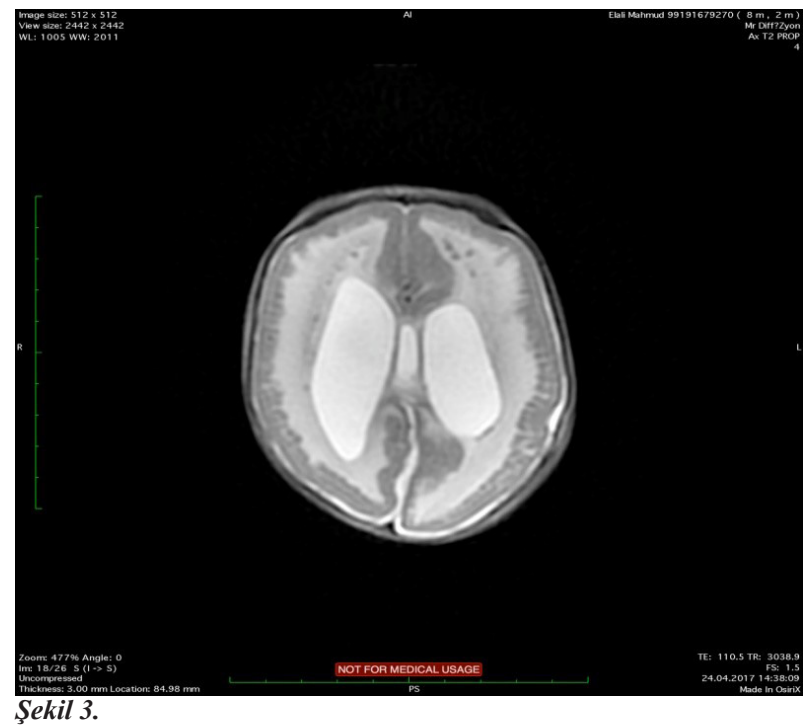

Bu bulgularla hastada Tip II Lizensefali-WalkerWarburg varyantı düşünüldü. Yapılan göz muayenesinde sağ gözde minimal katarakt, bilateral yaygın retina pigment epitel azlığ 1 ve optik disk atrofisi izlenmesi tanımızı güçlendirdi. Kas biyopsisinde alfa distroglikan eksikliği görülmesi ve ti- pik MR görüntüleri sebebiyle hastaya WWS tanıs1 konuldu. Yoğun bakım takibinde bronkopnömonisi düzeldiği halde hipotonisitesi nedeniyle mekanik ventilatörden ayrılamayan hastaya trakeostomi açıld1. Yatışının 64.gününde ev tipi mekanik ventilatör desteği ile taburcu edildi.

\section{TARTIŞMA}

WWS konjenital muskuler distrofiler içerisinde yer alan; göz ve beyin anomalilerinin eşlik ettiği otozomal resesif geçişli nadir görülen ve oldukça kötü prognozlu bir hastalıktır. Konjenital muskuler distrofili hastalar genelde doğduklarında hipotonik ve zayıflardır, serum CK düzeyleri yüksektir ve kas biyopsilerinde yaygın fibrozis, kas liflerinde dejenerasyon ve regenerasyon, yağ ve bağ dokuda proliferasyon görülür (2).

WWS'de üyesi olduğu distroglikanopatiler alfa distroglikanın post translasyonel modifikasyonunu sağlayan genlerde mutasyonla ortaya çıkar; konjenital muskuler distrofilerin genetik ve klinik olarak heterojen bir grubu kabul edilir. Alfa distroglikanın azalmış glikolizasyonu sonucunda kasta merozin, beyinde nöroksin gibi bağların bazal membran tutunması bozulmuştur. Sonuçta beyinde migrasyon bozuklukları, gözde yapısal anomaliler ve kaslarda distrofi meydana gelir (3).

CK yüksekliği, göz bulguları ve hipotonisitesi olan hastamızda, kas biyopsisinde alfa distroglikan eksikliği görülmesi ve tipik MR görüntüleri sebebiyle WWS tanisı konuldu.

Tanımlanmış bu grupta beyin ve göz anomalilerinin klinik olarak farklı şekillerde görüldüğü Fukuyama hastalığı, Walker Warburg Sendromu ve nispeten daha az mortal Muscle-Eye-Brain Hastal1$\breve{g} 1$ (MEB) vardır. Her üç hastalık da birbirine benzemekle birlikte beyin ve göz anomalilerin şiddeti ve etkileri farklıdır. En ağır seyreden WWS da ortalama yaşam ömrü dört aydır. Ancak literatürde 3 yaşına kadar yaşayan olgular vardır (4). WWS'de mikroftalmi, katarakt, optik sinir displazisi, retinal displazi gibi göz anomalileri; tip 2 lizensefali, serebellum ve ponsta hipoplazi, (bazen hidrosefalinin de eşlik edebildiği) ventriküler dilatasyon görülür (5). Nadir de olsa bizim hastamızda olduğu gibi ensafalosel görülebilir (6). Fukuyama hastalığında; hipotoni, gelişimsel gecikme, nöbetler, mikrosefali, lizensefali, optik atrofi görülmekle birlikte, bazen kardiyak anomalilerde eşlik edebilir (7). Beyin anomalilerinden septum pellisidum, korpus kallozum ve serebellar vermis agenezisinin WWS'li hastalarda FKMD'li hastalara göre daha sık görüldüğü saptanmıştır (8). Muscle-eye-brain (MEB) hastalığında ise hipotoninin yanında hastalarda infant döneminden itibaren şiddetli progresif miyopi görülür. Kraniyal görüntülemede WWS'den daha hafif olmak üzere lizensefali görülür, MEB'de beyin sap1 karakteristik olarak düzdür (9).

WWS'li bazı hastalarda yarık damak, yarık dudak, mikrotia, odotor kanal yokluğu, anorşi, renaldisplazi görülmüş olup değişik fenotiplerde karşılaşabileceğimiz unutulmamalıdır (10).

KMD'lerin büyük çoğunluğu otozomal resesif geçmekle birlikte de novo mutasyonlar ya da mo- 
zaizm sonucu otozomal dominant kalıtım da görülebilmektedir. KMD ile ilișkili tüm genetik testler yapılabilse de klinik olarak tespit edilebilme oranı \%20-46 arasında değişmektedir. Bu da KMD'lere yol açabilecek tüm genetik nedenlerin bilinmediğini doğrulamaktadır (2).

Next generation sekanslama konjenital muskuler distrofilerin tanımlanmasında gittikçe daha çok kullanılmaktadır. Böylece hastalığın etkilenmiş genleri hedef alınarak kitlesel parelel tekrar sekanslama yapilabilir yada direk tam ekzon sekanslama yapılabilir. Bu teknolojiler etkin ve efektif bir biçimde mutasyonun saptanmasına ve genetik olarak tanıyı koymaya yarar (11). Ancak şu an için bu teknolojilere ulaşmak kolay değildir ve maddi açıdan oldukça yüklüdür.

Sonuç olarak hipotonik infantların ayırıcı tanısında düşünülmesi gereken, otozomal resesif geçişli, ağır beyin ve göz bulgularının görüldüğü bu sendrom ve diğer konjential muskuler distrofilere tanı koymak akraba evliliklerinin de sık görüldüğü ülkemizde önem arz etmektedir. Böylelikle hastalara destek tedavisi erken dönemde başlanabilir ve gelişen teknoloji sayesinde indeks vakalar üzerinden genetik tanımlama yapılabilir.

Olgu 61. Türkiye Milli Pediatri Kongresi'nde Kasım 2017 tarihinde poster olarak sunulmuştur.

\section{KAYNAKLAR}

1. J. Vajsar, Harry Schachter. Walker-Warburg syndrome. Orphanet J. Rare Dis., 2016;1:29

2. Kang PB, Morrison L, Iannaccone ST, Graham RJ, Bönnemann CG, Rutkowski A et al. Evidence-based guideline summary: Evaluation, diagnosis, and management of congenital muscular dystrophy. Neurology. 2015;84:1369-1378.

3. R. D. Cohn. Dystroglycan: Important player in skeletal muscle and beyond. Neuromuscular Disorders, 2005;3:207-217.

4. Mercuri E, Messina S, Bruno C, Mora M, Pegoraro E, Comi GP et al. Congenital muscular dystrophies with defective glycosylation of dystroglycan: A population study. Neurology, 2009;21:1802-1809.

5. $\quad$ Semerci $C$, Şenel $S$, Okumus N, Talim B, Üner Ç, Göktaş $\dot{I}$ ve ark. Bir olgu nedeniyle Walker Warburg sendromu ve yeni görüşler. Gülhane Tip Derg., 2003.

6. Dobyns WB, Pagon RA, Armstrong D, Curry CJ, Greenberg F, Grix A,et al.. Diagnostic criteria for Walker-Warburg syndrome. Am. J. Med. Genet. 1989;2:195-210.

7. Falsaperla R, Praticò AD, Ruggieri M,Parano E, Rizzo, Corsello $G$,et al. Congenital muscular dystrophy: From muscle to brain. Italian Journal of Pediatrics, 2016;1:78

8. Kimura S, Sasaki Y, Kobayashi T, Ohtsuki N, Tanaka Y, Hara M,et al. Fukuyama-type congenital muscular dystrophy and the Walker-Warburg syndrome. Brain Dev., 1993;3:182191 .

9. Haltia M, Leivo I, Somer H, Pihko H, Paetau A, Kivelä Tet al. Muscle-eye-brain disease: A neuropathological study. Ann. Neurol., 1997;2:173-180.

10. R. Gershoni-Baruch, H. Mandel, B. Miller, P. Sujov, and J. Braun. Walker-Warburg syndrome with microtia and absent auditory canals. Am. J. Med. Genet. 1990;1:87-91.

11. Bönnemann CG, Wang CH, Quijano-Roy S, Deconinck N, Bertini E, Ferreiro Aet al. Diagnostic approach to the congenital muscular dystrophies. Neuromuscul. Disord. 2014;4: 289-311. 